\title{
Dış Göçler Olgusu ve Etkisi: Türkiye-Suriye Üzerine Bir İnceleme ${ }^{1}$
}

Dicle BOZ, Department of Economics, Faculty of Economics and Administrative Sciences, Dokuz Eylul

University,Turkey; e-mail: diclee_1722@hotmail.com

\section{Foreign Immigration Cases and Effects: An Investigation on the Turkey- Syria $^{2}$}

\begin{abstract}
Migrations are social happenings that deeply affect the structure of communities and leave permanent marks. Turkey has been the leading actor of a possibly universal movement of migration in the last few years. The purpose of this study is to determine the changes invoked by the intense migration in Turkey in the recent period on social life, especially on economics, and to examine the economic developments in Turkey from a different perspective, in its experience as a "migrationreceiving" country.

Keywords $\quad$ : Emigration, Syria Crisis, Turkey, International Migration.

JEL Classification Codes : F00, F10, F20.

$\ddot{\mathbf{O} z}$

Göçler, toplumların yapısını derinden etkileyen, kalıı izler bırakan sosyal olaylardır. Türkiye, son yıllarda evrensel nitelikte olabilecek bir göç hareketinin başrolüdür. Bu çalışmanın amacı ise son dönemde Türkiye'de yaşanan yoğun göçün başta ekonomik alanda olmak üzere toplumsal hayatta yarattı̆̆ değişimleri saptamak, "göç alan” ülke deneyimiyle Türkiye'deki ekonomik gelişmeleri farklı bir perspektiften incelemektir.
\end{abstract}

Anahtar Sözcükler $\quad$ : Dış Göç, Suriye Krizi, Türkiye, Uluslararası Göç.

I Bu makale, Dokuz Eylül Üniversitesi İktisadi ve İdari Bilimler Fakültesi İktisat Bölümü tarafindan düzenlenen "Prof.Dr. Mehmet Sadık ACAR Bilimsel Araştırma ve Lisansüstü Tez Yarışması-2016" kapsamında ü̧̈üncülük ödülüne laylk görülmüştür.

2 This paper had won the "Third Place" in "Prof.Dr. Mehmet Sadlk ACAR Scientific Research and Thesis Competition-2016" organized by Dokuz Eylul University, Faculty of Economics and Administrative Sciences, Department of Economics. 


\section{Giriş}

Genel bir ifadeyle göç "kişilerin yerleşmek amacıyla bir iskân ünitesinden diğerine giderek meydana getirdikleri yer değiştirme hareketidir (Nakhoul, 2014: 4). Fakat kişileri, toplulukları bu eyleme iten sebepleri göz önüne alıp daha derinlemesine bir tanım oluşturulmak istendiğinde insanların tarih boyunca olumsuz doğa koşullarından kurtulmak, baskılardan kaçmak, daha güvenli ortamlarda yaşamak, sosyal ortamlar yaratmak ve yaşamlarını daha uygun koşullarda sürdürmek için yaşadıkları yerleri bırakıp yeni yaşam alanlarına yerleşmesi" şeklinde bir tanım yapılabilmektedir (Ünal, 2014: 66).

Göç olgusu her ne kadar insanın en eski dönemlerinden beri devam etse de zaman içinde değişmiş ve özellikle son dönemlerde artış göstermiştir. Birleşmiş Milletler'in 2013 sonunda açıkladığ1 Küresel Göç Raporu İstatistikleri'ne göre dünya üzerindeki uluslararası göçmen sayısı her geçen yıl artmaktadır. 1910 yılında kendi ülkeleri dışında yaşayan göçmenler olarak nitelenen bireylerin sayısı 33 milyondu. Rapora göre uluslararası göçmenlerin sayısı 1990 senesinde 154 milyon iken 2000'de 175 milyona, 2010'da 221 milyona ve 2013 'te 232 milyona ulaşmıștır. Bu sayı dünya nüfusunun \%3,2 sini oluştururken aynı zamanda dünya tarihinde ulaşılan en yüksek göçmen sayısını ifade etmektedir (Ünal, 2014: 66). Göçmen sayısının zaman içinde bu denli hızlı artması, içinde bulunduğumuz bilgi çağının küreselleşme ile şekillenmesiyle açıklanabilmektedir. Dünya bilim ve teknolojide yaşanan büyük gelişmelerle daha küçük hale gelmiş, gelişmişlik seviyeleri yükselmiş ve sınırlar daha kolay aşılır hale gelmiştir.

Uluslararası göçlerin artışındaki bir diğer etken ise küreselleşme ile birlikte zenginliğin dünyanın gelişmiş ülkelerinde, yoksulluğun ise az gelişmiş ya da gelişmekte olan ülkelerde yoğunlaşması sonucu ülkeler arasındaki gelir dağılımı adaletinin bozularak; yoksulluğun önemli ölçüde artmış olmasıdır (Gökbayrak, 2006: 3).

Göçler, yaşandıkları coğrafyalarda kısa ve uzun vadede büyük değişiklikler yaratırlar. Uluslararası göçlerin böylesine fazla yaşanması, gelişmekte olan ve özellikle de gelişmiş ülkeler için gerek etnik gerekse sosyo-ekonomik açıdan tehdit unsuru oluşturmaktadır. Bunun en somut örneği olarak son yıllarda Avrupa'ya yapılan yoğun göçün Avrupa toplumu üzerinde yarattığı değişimler gösterilebilir. Sosyal açıdan incelendiğinde ulusal kimliğin hasar görmesi, sosyal devlet yapısında meydana gelebilecek olumsuz etkiler nedeniyle toplumda meydana gelen endişe ve önyargı göçmenlere karşı tutumu olumsuz yönde etkilemiştir. Yine ekonomik açıdan incelendiğinde işgücünün ucuzlaması dolayısıyla hali hazırda istihdam edilen nüfusun gelirinin azalması gibi olumsuz etkileri görülmektedir. $\mathrm{Bu}$ gibi durumlar göçmen alan toplumların sosyal yapısını büyük ölçüde etkilemiş, ekonomik açıdan yapısal değişiklikleri zorunlu hale getirmiştir.

\section{Uluslararası Göç ve Türkiye Üzerindeki Etkisi}

Türkiye, göçmen veren ülke ile göçmen alan ülke bağlamında bakıldığında 1960'lı yıllarda Batı Avrupa ülkelerinin ucuz işgücü ihtiyacını karşılayan ve dolayısıyla uzunca yıllar bu ülkelerin işgücü deposu olarak görülen "göç veren" ülke konumundaydı. Fakat son 
yıllarda özellikle küreselleşme ve ülkede 1980 sonrası yaşanan liberal ekonomik gelişmeler sonucu, yabancı ülke vatandaşlarının iş bulmaları halinde, uluslararası öğrenci statüsünde veya emekli olarak Türkiye'de oturma ve çalışma izni edinmeleri sıklıkla rastlanan durumlardandır (Ünal, 2014: 70). Şimdi ise coğrafi konumu ve sınırında yaşanan gelişmeler düşünüldüğünde Türkiye, hem Asya'dan ve Ortadoğu'dan Avrupa'ya göç eden nüfus için mecburi bir durak hem de hedef ülke konumundadır. 20. yüzyılın ortalarından bu yana kendi vatandaşları yurtdışına göç eden bir ülke olan Türkiye artık başka ülke vatandaşlarının göç ettiği ve çalıştığı bir ülke olmaya başlamıştır (Deniz, 2014: 184). Türkiye yaşadığı bu yeni göç alan ülke deneyimiyle ele alındığında durumun kavranması açısından verilebilecek en iyi örnek Suriye krizi nedeniyle yaşanan göç dalgasıdır. Sözü edilen göç dalgası kapsamında Türkiye bir yandan göç alan, bir yandan ise gelen göçmenlere geçiş alanı yaratan bir ülke konumuna gelerek daha kalıcı bir göçmen nüfusa sahip olmuştur. Ancak, öncelikle göçmenlik ile mültecilik veya sığınmacılık arasında bir takım farklar bulunduğunu belirtmek gerekmektedir. Mülteci ve sığınmacıyı göçmen olarak adlandırabilmekle birlikte her göçmen kişiyi sığınmacı ve mülteci olarak tanımlamak mümkün değildir. Göçmen, yaşadığı ülkesini kendi isteğiyle daha iyi yaşam koşullarına ulaşmak amacıyla terk eden kişi olarak kabul edilirken (Ünal, 2014: 71), mülteci için daha farklı bir tanım söz konusudur. Kapsamlı tanımı 1951 tarihli Mültecilerin Hukuki Durumuna İlişkin Cenevre Sözleşmesi'nde yer almaktadır. Buna göre; "Menşei ülkesi dışında bulunan, ırkı, dini tabiiyeti, beli bir toplumsal gruba mensubiyeti veya siyasi görüşü sebebiyle zulüm görmekten haklı nedenlerle korku duyan ve ülkesinin korunmasından yararlanamayan ya da yararlanmak istemeyen veya zulüm korkusu nedeniyle buraya dönmek istemeyen kişi “mülteci” olarak tanımlanır (Tunç, 2015: 32).

Suriye Krizinin başladığı 2011 yılında Birleşmiş Milletler Mülteciler Yüksek Komiserliği'nin (BMYK) verilerine göre en fazla mülteci ağırlayan ilk 10 ülke arasında yer almayan Türkiye, 2014 yılı itibariyle mülteci ağırlayan ülkeler listesinde dördüncü sırada yer almaya başlamıştır. Mülteci ağırlayan ülkeler sıralamasında BM'nin Ocak 2015 tahminlerine göre birinci, Aralık 2015 tahminlerine göre ise ikinci sırada yer alması öngörülmektedir (Tunç, 2015: 31).

Bu denli hızlı büyüyen ve yayılan bir göç hareketinin yaşandığı Türkiye'de elbette olumlu-olumsuz çok büyük etkiler oluşması muhtemeldir. Her ne kadar durumun olumlu sonuçları mevcutsa da hem göçmenler hem de göç alan toplum için zor bir deneyimdir. Bunun etkilerini başta sosyal hayatta görmek mümkündür. Stanley’e göre mültecilerin, göç alan ülkeye yerleşebilmelerindeki ve uyumlarındaki başarı ya da başarısızlıkları, o ülkedeki hükümetlerin ve toplumların tutumlarına, göç politikalarına, göçmen-mültecilere yönelik yerleşme ve destek programlarına ve son olarak göçmen-mültecilerin fizik ve ruh sağlıklarına yönelik kolaylaştırıcılıklarına bağlı olmaktadır (Tunç, 2015: 33). Öte yandan göç eden kitlenin hedef ülkenin diline, eğitim sistemine, ekonomik hayatına alışma süreci de bu uyumun önemli unsurlarını oluşturmaktadır. 


\section{Dış Göçün Ekonomik Yaşam Üzerindeki Etkisi}

Göç olgusu hem kaynak ülke hem de hedef ülke için olumlu sonuçlar ortaya çıkarabilir. Türkiye açısından bakıldığında, göç alan ülkenin hiçbir yatırımda bulunmadan, kaynak harcamadan, sıfır maliyetle işgücü piyasasının ihtiyaç duyduğu kişiyi, ihtiyaç duyduğu sürece çeşitli eleme süreçlerinden geçirerek istihdam etmesi açısından göçün hedef ülkeye olumlu etkileri olduğu söylenebilir. Diğer yandan nüfusun gençleşmesi, işgücü piyasasının ihtiyaçlarına cevap verilmesi ile ekonominin kalkınması, ekonomik faaliyetlerin gelişip çeşitlenmesi, nitelikli işgücü ithal ederek bilim ve teknolojide ilerlenmesi de göç alan ülkenin diğer kazanımlarıdır. Bu noktada göz ardı edilmemesi gereken husus tüm bu kazanımların, hedef ülkeye yasal yollardan yapılan işgücü göçü ile sağlanmasıdır (Nakhoul, 2014: 12).

Türkiye'nin şimdiki durumu göz önüne alındığında Suriye'de yaşanan iç savaş nedeniyle ülkeye yapılan göçün zorunlu nitelikte olması, duyulan işgücü ihtiyacından oldukça fazla olması yerleşik çalışan nüfusu da olumsuz etkilemiştir. Ekonomik hayata katılmak isteyen mülteciler, emek arzını arttırmış bu da emek gelirinin düşmesine yol açmıştır. Ayrıca Suriyelilere çalışma izni verilmesi özellikle Suriyeli nüfusun yoğun bulunduğu illerde işgücü piyasasındaki rekabeti arttırmış, işsizlik üzerinde olumsuz bir etki yaratmıştır.

Şekil: 1

\section{Suriye Nüfusu ve İşsizlik Oranları \%2015}

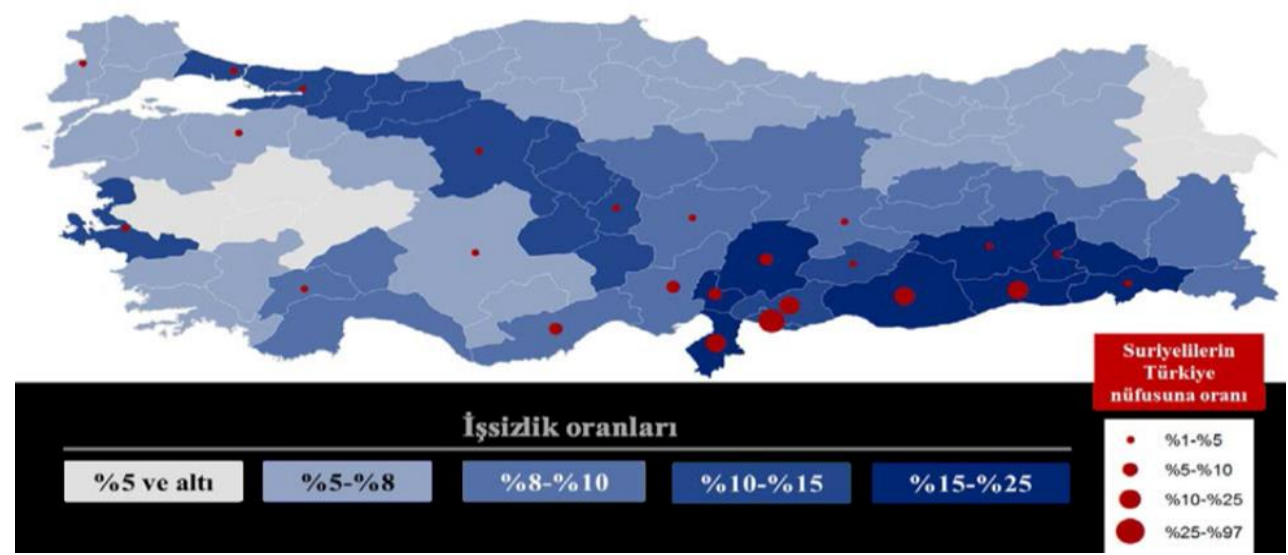

Kaynak: Özpınar vd., 2016.

Görsele bakıldığında Gaziantep, Kilis, Hatay ve Adıyaman gibi Suriyeli nüfusunun fazla olduğu illerde emek piyasasındaki rekabetin yoğun olduğu görülür. Bu durum toplum üzerinde Suriyelilerin işlerini ellerinden aldıkları yönünde bir algı oluşturmaktadır. 
Öte yandan, Suriye'den göçlerin başlamasıyla mültecilerin barınma ihtiyaçlarının giderilmesi için Suriye sınırına yakın illerde 8 çadır kent ve 1 konteynır kent kurulmuştur. Burada sığınmacıların barınma ve sosyal ihtiyaçları karşılanmaya çalışılmıştır. Sığınmacıların Türkiye'ye gelmeye başladığı Nisan 2011'den Haziran 2012'ye dek bu kamplar için harcanan para 200 milyon lirayı geçmiştir. Şekil 2 ye bakıldığında ise 20022012 yılları arasında yapılan bütçe harcamalarının il bazındaki düzeyi görülmektedir.

Şekil: 2

\section{Suriye Krizinden Doğrudan Etkilenen 14 Komşu İlin Merkezi Bütçe Giderleri}

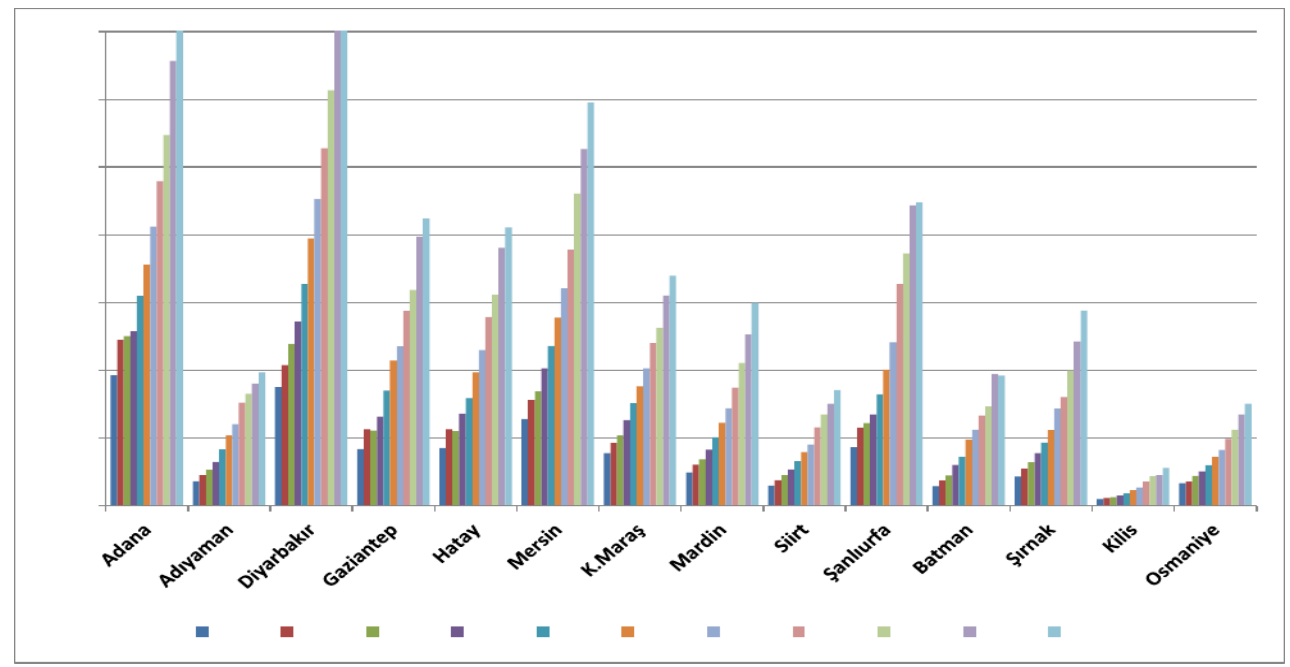

Kaynak: Maliye Bakanlı̆gl, Muhasebat Genel Müdürlü̆̈̈̈, <www.muhasebat.gov.tr>.

2002-2012 döneminde genel bütçe giderleri önemli oranda artmıştır. Sosyal güvenlik transferleri, faiz harcamaları, personel giderleri gibi merkezi harcamalar çıkarıldığında, 2002 yılında 81 ile yaklaşık 40 milyar TL kaynak aktarılırken 2012 yılında bu miktar 160 milyar TL'ye çıkmıştır. Gerek 2011 gerekse 2012 yıllarında, bölgede yer alan illere tahsis edilen bütçe kaynakları artmıştır. 2010 yılında bölgeye toplamda 19,5 milyar TL kaynak aktarılırken 2011'de 23,2 milyar TL, 2012 yılında 25,2 milyar TL bütçe gideri olmuştur. Vergi gelirlerine yüzde 5 - 6 düzeyinde katkı sağlayan bölge, bütçe giderlerinden yüzde 1516 civarında pay almaktadır. Bölge içerisinde en fazla kaynak aktarılan il 3,8 milyar TL ile Diyarbakır olmuştur. Diyarbakır'1 3,6 milyar TL ile Adana, 3 milyar TL ile Mersin ve 2,2 milyar TL ile Şanlıurfa takip etmektedir (Taşçı \& Özsan, 2013: 16).

Öte yandan Suriyeli mültecilerin 2011-2012 yılında ülkemizde barınma ve diğer ihtiyaçlarından kaynaklanan maliyet 2,7 milyar TL olmuştur. 2013 yılı boyunca mültecilerin Türkiye'de kalması durumunda, 2013 yılı sonu itibarıyla maliyet 3,54 milyar TL'ye, kişi başına düşen maliyet ise 47 TL'ye yükselecektir. Suriye'den gelen turist sayısında yaşanan azalmanın ekonomik maliyeti 322 milyon TL'dir. Kişi başına düşen maliyet hesaplandığında, ekonomik kaybın 4,3 TL olduğu görülmektedir (Taşçı \& Özsan, 2013: 29). 
Her ne kadar sığınmacılar için barınma ihtiyacı önemli ölçüde karşılansa da orta halli ve üst gelir grubundaki sığınmacıların artan kiralık ev talepleri, bölgedeki illerde kiraların yükselmesine yol açmıştır. Sığınmacıların kiralık konut için hedeflerindeki illerden biri olan Gaziantep'teki Tüm Emlakçılar Odası Başkanı Mehmet Aytaç'ın yaptığı açıklamaya göre, ilde son 3-4 aylık süreçte kiralar 3 katına çıkmıştır. Antep dışında Hatay, Kilis ve Adana'daki evlerin de orta halli göçmenlerden talep gördüğü, daha zengin göçmenlerin ise Mersin’i tercih ettikleri ifade edilmiştir (Alpaslan, 2012: 11).

Arap Baharı, bölge sermayesinin Türkiye'ye girişini Mart 2011'den itibaren hızlandırmıştır. Ülkeye son yıllarda giren Suriyeliler de göz önüne alındığında 2010 yılı sonunda yapılan açıklamalara göre yabancıların Türk bankalarındaki mevduatı 20 milyar dolara yaklaşmıştır. Bu tutarın yaklaşık beşte birini ise İranlılar getirmiştir. 2011 yılı sonlarına doğru ise, yabancıların Türkiye'deki mevduatları \%50 civarında bir artışla 25 milyar doları aşmıştır. Bankacıların yaptıkları açıklamalara göre Türkiye'nin güvenli bir liman olarak görülmesi, sermayenin akışının önemli nedenlerinden biri olmuştur. Her ne kadar Arap Baharı Türk bankalarındaki mevduat stokunu arttırıcı bir etki göstermiş olsa da, diğer yandan bölge ülkeleri ile çalışan firmaları finansman sıkıntısına sürüklemiştir (Alpaslan, 2012: 11).

Ayrıca son zamanlarda Suriye sınırına yakın illerde kurulan şirket sayıları incelendiğinde, 2011'den itibaren açılan Suriyeli ortaklı şirket sayısında artış görülmektedir. Açılan şirketlerde istihdam edilenlerin etnik kimliklerine ilişkin bir veri bulunmamasına karşılık, ucuz işgücü ve sosyal dayanışma çerçevesinde Suriyeli şirketlerin Suriyelileri istihdam etmesi düşünülebilir. Bu durum, kayıt dışı ekonomi ile istihdam edilen kişi sayısında artış ve dolayısıyla kayıt içi ekonomide istihdam azalışı görülmesine neden olabilir. Buna karşılık, artan şirket sayıları ile kendi işini yapan Suriyeliler işgücü artışında bir paya sahip olabilirler (Özpınar vd. 2016: 3).

Yaşanan kriz ve mülteci akını sonrası Suriye ile ithalat ve ihracat da önemli ölçüde etkilenmiştir. Özellikle Suriyelilerle yoğun ilişki içinde bulunan illerin ekonomisi yavaşlamış, ticaret hacmi düşmüştür. Bu durum istihdamı da olumsuz yönde etkilemiştir.

Netice itibari ile son yıllarda yoğunluğu giderek artan bu büyük göç olayının Türkiye ekonomisi üzerinde olumsuz etkilerini her gün biraz daha fazla hissetmek mümkündür. Bu durum sosyal hayattaki çatışmaları da beraberinde getirebilmektedir. Olası toplumsal kargaşaların ve kutuplaşmaların önüne geçmek amacıyla Suriyeli nüfusu sağlam temeller üzerine kurulmuş politikalar aracılığı ile ekonomik hayata dâhil etmek bir mecburiyet halini almıştır.

\section{Sonuç}

Türkiye'nin ve dünyanın gördüğü en büyük göç olaylarından biri olan Suriyeli mülteci krizi Türkiye’yi büyük ölçüde etkilemiştir. Mültecilerin yerleşmek için Türkiye'yi tercih etmesi Türkiye'yi hukuksal, sosyal, ekonomik ve daha birçok alanda düzenlemeler yapmaya itmiştir. Mültecilerin ağırlıklı yerleştiği alanlara özellikle büyük bütçeler ayrılmış, 
barınma ihtiyaçlarından sosyal ihtiyaçlarına kadar birçok ihtiyaçları karşılanmaya çalışılmıştır.

Suriye tekrar vatandaşlarını ağırlayabilecek konuma gelse bile mültecilerin bir kısmı düzenini bozup gitmek istemeyecektir. Bu durum göz önüne alındığında Suriyelilerin ekonomik hayata entegrasyonu söz konusu olmaktadır. Bunun için mülteci nüfusunun yoğunluklu olduğu alanlarda iş kapasitesi arttırılmalıdır. Böylelikle iş hayatına katılamayan Suriyelilerin suç oranlarını arttıracaklarına dair endişe de ortadan kalkacaktır.

Öte yandan herhangi bir politika uygulanmaksızın Suriyeli nüfusun ekonomik hayata katılımı dış ticaretten emlak sektörüne, turizmden lojistik sektörüne kadar birçok ekonomik alanda Türkiye'yi olumsuz sonuçlarla karşı karşıya bırakmıştır.

Sonuç olarak, durumu hem Türkiye hem mülteciler lehine çevirmek için başta eğitim olmak üzere diğer alanlarda da Suriyelileri toplumsal hayata katmalı, güven duygularını pekiştirecek şekilde sosyal-ekonomik yaşamda yer tutmalarını sağlamalıdır.

\section{Kaynaklar}

Alpaslan, İ.B. (2012), “Suriye Krizi Türkiye Ekonomisini Nasıl Etkiler?”, Türkiye Ekonomi Politikaları Araştırma Vakfi, Değerlendirme Notu, N. 201148, Ağustos, $<$ http://www.tepav.org.tr/upload/files/1345630741-

9.Suriye_Krizi_Turkiye_Ekonomisini_Nasil_Etkiler.ppd>, 05.05.2016.

Deniz, T. (2014), “Uluslararası Göç Sorunu Perspektifinde Türkiye”, Türkiye Sosyal Araştırmalar Dergisi, 18(1), 175-204.

Gökbayrak, Ş. (2008), "Uluslararası Göç ve Kalkınma Tartışmaları: Beyin Göçü Üzerine Bir İnceleme”, Ankara Üniversitesi SBF Dergisi, 63(3), 65-82.

T.C. Maliye Bakanlığg, Muhasebat Genel Müdürlüğü (2013), <www.muhasebat.gov.tr>, 06.05.2016.

Nakhoul, T.E. \& F. Kartal (2014), “Uluslararası İşgücü Göçü ve Türkiye”, Uzmanlık Tezi, T.C. Çalışma ve Sosyal Güvenlik Bakanlığı, Ankara.

Özpınar, E. \& Y.S. Çilingir \& A.T. Düşündere (2016), “Türkiye'deki Suriyeliler: İşsizlik ve Sosyal Uyum”, Türkiye Ekonomi Politikaları Araştırma Vakfi, Değerlendirme Notu, $<$ http://www.tepav.org.tr/upload/files/1461746316-

7.Turkiye__deki_Suriyeliler__Issizlik_ve_Sosyal_Uyum.pdf>, 06.05.2016.

Taşc1, K. \& M.E. Özsan (2013), Suriye Krizinin Türkiye Ekonomisine Etkisinin Analizi (2011-2013), <<https://www.researchgate.net/profile/Kamil_Tasci/publications>, 05.05.2016.

Tunç, A.Ş. (2015), "Mülteci Davranışı ve Toplumsal Etkileri: Türkiye'deki Suriyelilere İlişkin Bir Değerlendirme", Tesam Akademi Dergisi, 2(2), 29-63.

Ünal, S. (2014). “Türkiye'nin Beklenmedik Konukları: ‘Öteki’ Bağlamında Yabancı Göçmen ve Mülteci Deneyimi”, Journal of World of Turks/Zeitschrift für die Welt der Türken, 6(3), 65-89.

Yı1maz, A. (2014), “Uluslararası Göç: Çeşitleri, Nedenleri ve Etkileri”, Turkish Studies, 9(2), Ankara, 1685-1704. 
Boz, D. (2016), "Dış Göçler Olgusu ve Etkisi: Türkiye-Suriye Üzerine Bir İnceleme", Sosyoekonomi, Vol. 24(30), 147-153. 